\title{
Selective Detection of Dopamine in the Presence of Ascorbic Acid at Poly (m-Aminobenzene Sulfonic Acid)
}

\author{
Gamze Erdoğdu, ${ }^{1, *}$, Mehmet Mutluhan Mutlu² \\ ${ }^{1}$ Department of Chemistry, Faculty of Arts and Sciences, İn̈nü University, Malatya, Turkey \\ ${ }^{2}$ Department of Chemistry, Faculty of Arts and Sciences, Harran University, Şanliurfa, Turkey \\ E-mail: gerdogdu@inonu.edu.tr \\ Received August 4, 2010; revised October 26, 2010; accepted May 1, 2011
}

\begin{abstract}
Poly ( $m$-aminobenzene sulfonic acid, $m$-ABSA) films were electrochemically prepared by cyclic voltammetry $(\mathrm{CV})$ in $0.1 \mathrm{~mol} \mathrm{~L}^{-1} \mathrm{KCl}$ solution. The dopamine (DA) selectivity of polymeric electrodes prepared at the different thicknesses was examined in the presence of ascorbic acid (AA). The results showed that the modified electrode showed an excellent electrocatalytical effect towards oxidation of dopamine (DA) and ascorbic acid (AA). Electrostatic interaction between the negatively charged poly $(m-\mathrm{ABSA})$ film and either cationic DA species or anionic AA species favorably contributed to the redox response of DA and AA. Moreover, the regular and repetitive responses for dopamine were obtained even in the presence of the some interfering substances such as ascorbic acid, $\mathrm{NaCl}, \mathrm{NaClO}_{4}, \mathrm{Na}_{2} \mathrm{SO}_{4}, \mathrm{NaNO}_{3}$ and $\mathrm{KCl}$.
\end{abstract}

Keywords: Poly (m-Aminobenzene Sulfonic Acid), Dopamine, Ascorbic Acid

\section{Introduction}

Among the catecholamines, DA has attracted most interest, because the change in DA levels has proved to be a very effective route toward understanding brain functions, such as learning and memory formation, and physiological and pathological process of Parkinson's disease $[1,2]$. All attempts to measure neurotransmitters, particularly DA, in the brain with voltammetric procedures require the use of several strategies to improve the qualitative and quantitative aspects of these measurements. The main problem associated with in vivo measuring of levels of this monoamine is the very low DA concentration $\left(10^{-8}-10^{-6} \mathrm{M}\right)$ and the large excesses of interfering species such as ascorbic acid (AA) (about 0.1 M). As well known, a major problem encountered with the detection of DA is the interference from ascorbic acid (AA), which largely coexists with DA in brain issue and has an overlapping oxidation potential on the solid electrodes, so it is very difficult to determine DA directly [3]. In order to resolve this problem, many different strategies have been used to modify the electrode, which include self-assembled monolayer [4], electrochemical pretreatment [5], polymer film [6-17] and covalent modified [18]. It is well known that DA exists as a cation at physiological $\mathrm{pH}$ 7.0, while AA exists as an anion [19].
It is a possible way to overcome this problem by coating the electrodes with a thin film of Nafion [20-22]. The $\mathrm{SO}_{3}^{-}$of Nafion film can repel AA anion to eliminate interference of AA. The kind of electrode usually suffers from a slow response due to low diffusion coefficients $[23,24]$ of analytes in the films. The other method is to cover the electrode surface with double-layer film [25-27]. This kind of modified electrode is coated first with an electroactive material having catalytic effect on the oxidation of DA and then with a Nafion layer. Another approach is to cover the electrode surface with electropolymerized films.

In this paper, we apply $m$-ABSA as a modifier to fabricate polymer modified electrodes by electropolymerization method. In $m$-ABSA, there are electron-rich $\mathrm{N}$ atom and high electron density of sulfonic group. Hence, the poly ( $m$-ABSA) film is negatively charged. The modified electrodes show an electrocatalytic activity for the oxidation of DA and AA. The obvious separation of potential to DA and AA can be obtained at modified electrode. It means that AA has no interference for detection DA. On the contrary, $\operatorname{poly}(m$-ABSA) film modified glassy carbon electrode was utilized for electrocatalytic effect on the electrooxidation of DA in the presence of $\mathrm{AA}$ at physiological $\mathrm{pH}$. The modified electrode showed good stability and reproducibility. 


\section{Experimental}

\subsection{Materials}

$m$-aminobenzen sulfonic acid was purchased from Merck and was used without any further purification. All the other chemicals used such as dopamine hydrochloride, ascorbic acid and $\mathrm{KCl}$ were of analytical grade and purchased either from Sigma Chemical Company (St. Louis, MO, USA) or from Merck (Darmstad, Germany). Monomer solutions were purged with nitrogen gas for about 10 min before polymerization and the solution was blanketed with the same gas during electropolymerization. Amperometric measurements were performed in a PBS (phosphate buffer salts, $\mathrm{pH}=7.0$ ) solution. Dopamine and ascorbic acid solution were prepared freshly before experiment. All aqueous solutions were prepared with deionized and doubly distilled water.

\subsection{Instrumentation}

An electrochemical workstation BAS $100 \mathrm{~W}$ (Bioanalytical Systems, Inc. West Lafeyette, IN, USA) equipped with a personel computer was used for electropolymerization, cyclic voltammetry (CV) and differential pulse voltammetry (DPV) experiments. All electrochemical studies were performed using a conventional threeelectrode system consisted of a bare or polymer modified glassy carbon working electrode (geometric area: 6.85 $\mathrm{mm}^{2}$ ), a $\mathrm{Ag} / \mathrm{AgCl}$ reference electrode and a $\mathrm{Pt}$ wire coil auxiliary electrode. All electrolysis and voltammetric experiments were made at room temperature. In the cyclic voltammetry experiments the scan rate was $50 \mathrm{mV} / \mathrm{s}$.

\subsection{Preparation of Poly (m-Aminobenzene Sulfonic Acid) Film}

Prior to electrochemical modification, the bare GCE with a diameter of $0.3 \mu \mathrm{m}$ was polished with diamond pastes and alumina slurry down to $0.05 \mu \mathrm{m}$ on a polishing cloth. Then it was rinsed with double-distilled water, and sonicated in 1:1 nitric acid, acetone and double-distilled water for $10 \mathrm{~min}$, respectively. Then it was electrochemically activated by using 20 times cycling potential sweeps in the range of -0.5 to $2.0 \mathrm{~V}$ in $0.1 \mathrm{M} \mathrm{H}_{2} \mathrm{SO}_{4}$ solution at a scan rate of $100 \mathrm{mV} / \mathrm{s}$. After being cleaned, the electrode was immersed in $0.1 \mathrm{M} \mathrm{KCl}$ solution containing $5.0 \mathrm{mM} \mathrm{m}$-ABSA and was conditioned by cyclic sweeping from -2.0 to $2.5 \mathrm{~V}$ at $50 \mathrm{mVs}^{-1}$ for 14 scans. After that, the modified electrode was electroactivated by cyclic voltammetry from -0.5 to $0.5 \mathrm{~V}$ at $100 \mathrm{mVs}^{-1}$ in pH 7.0 PBS.

\section{Results and Discussion}

\subsection{Electropolymerization of $\mathrm{m}-\mathrm{ABSA}$ at the GCE Surface}

Voltammograms of $5.0 \mathrm{mM} \mathrm{m}-\mathrm{ABSA}$ in $0.1 \mathrm{M} \mathrm{KCl}$ solution at a GCE are shown in Figure 1. From the first

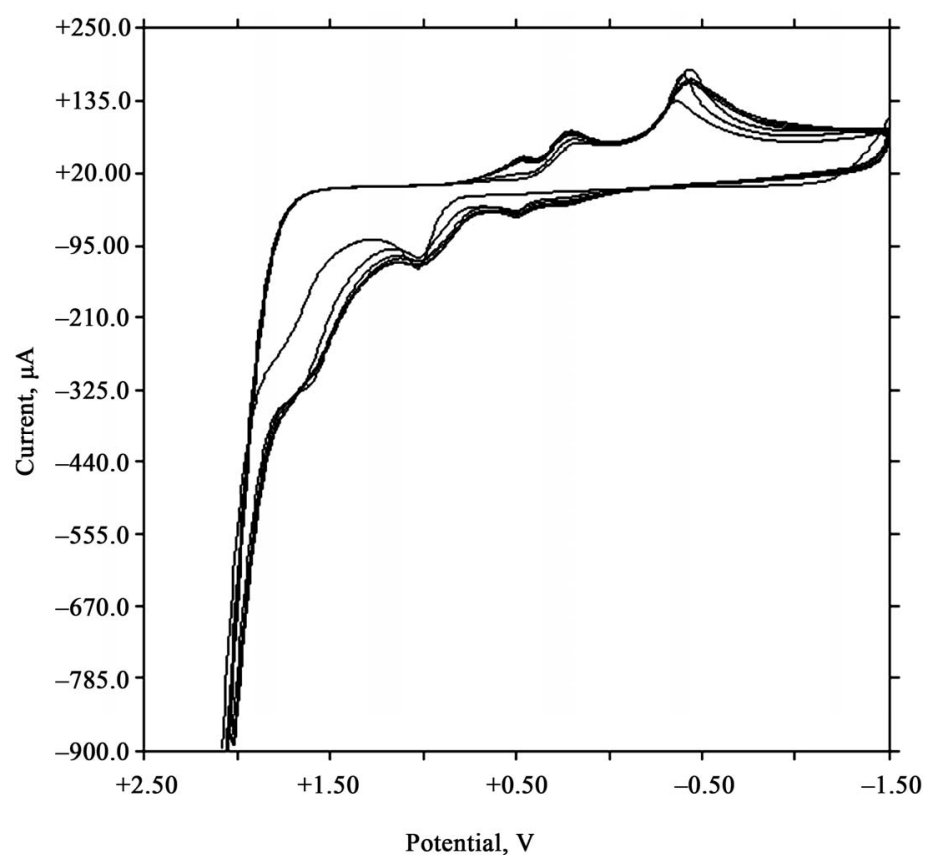

Figure 1. Repetitive cyclic voltammograms of $5.0 \mathrm{mM}$ m-ABSA in $0.1 \mathrm{M}$ KCl solution. Initial potential: -1.5 V; terminal potential: $+2.5 \mathrm{~V}$; sensitivity: $1.0 \times 10^{-4} \mathrm{~A} \mathrm{~V}^{-1}$. 
cycle, an anodic peak (a) at. $0.510 \mathrm{~V}$ increased gradually until the third cycle, and then a new anodic peak (c) appeared at $1.027 \mathrm{~V}$. A cathodic peak (b) appeared in the first cycle with a potential at $-0.510 \mathrm{~V}$, then a new cathodic peak (c) appeared at $0.199 \mathrm{~V}$. Then larger peaks were observed on continuous scanning, reflecting the continuous growth of the film. These facts indicated that $m$-ABSA was deposited on the surface of GCE by electropolymerization. After modification, the poly( $m$-ABSA) film electrode was carefully rinsed with doubly distilled water and then stored in air and prepared to use later.

\subsection{Electrochemical Response of $\mathrm{DA}$ and $\mathrm{AA}$ at Poly(M-ABSA) Film Modified Electrode}

Figure 2 shows cyclic voltammograms of DA and AA in pH 7.0 phosphate buffer solution at a bare GCE and a poly ( $m$-ABSA) film modified GCE. The electrochemical response of DA and AA at the bare GCE produce an anodic peak at the potentials of 0.192 and $0.184 \mathrm{~V}$, respectively; the peak potentials are very close and nearly overlap. But at the poly ( $m$-ABSA) film modified electrode, it could be observed that the modification shifts the oxidation potentials of DA and AA toward signifycantly negatively potentials. In pH 7.0 PBS, DA exists as a cation with a positively charged amino group ( $\mathrm{pKa} 8.9$ ) [28] while $m$-ABSA is nonprotonated. Hence, the oxidation of DA might be ascribed to the electrostatic attracttion interaction between DA cations and the high electron density of sulfonic group of $m$-ABSA, such an interaction would lead to the increase in concentration of DA around the surface of the modified electrode. Similar results also reported in literatures [29].

\subsubsection{Effect of Scan Rate and $\mathrm{pH}$ on Oxidation of DA}

The effect of scan rate on the oxidation peak current of $1.0 \mathrm{mM}$ DA was studied. With the scan rate increasing, the anodic peak current $\left(i_{\mathrm{pa}}\right)$ increased. A good linearity between the square root of scan rate and $i_{\mathrm{pa}}$ was obtained within the range of 10 to $200 \mathrm{mVs}^{-1}$. The linear regression equation was $i_{\mathrm{p}}(10 \mu \mathrm{A})=-0.9991+2.0446 \mathrm{~V}^{1 / 2}$ $\left(\mathrm{mVs}^{-1}\right)$ with the correlation coefficient $r^{2}=0.9945$. The result indicates that the electrode process is controlled by the diffusion of DA.

The effect of $\mathrm{pH}$ on the peak potential and current was investigated by differential pulse voltammetry in the presence of $1 \mathrm{mM}$ DA in $0.1 \mathrm{M}$ phosphate buffer solution. The peak potential $\left(\mathrm{E}_{\mathrm{pa}}\right)$ shifted negatively when the $\mathrm{pH}$ changed from acid over neutral to basic. The plot of $\mathrm{E}_{\mathrm{pa}}$ versus $\mathrm{pH}$ shows linearity in the $\mathrm{pH}$ range of 5.0 to 8.0 with a slope of $-23.51 \mathrm{mV} \mathrm{pH}^{-1}$, revealing that the proportion of the electron and proton involved in the reactions is $1: 1$. Because the DA oxidation is a two- electron process, the number of protons involved is also predicted to be two. This accords with the mechanism of DA oxidation as reported previously [30,31] It can also be seen from Figure 3 that the peak current of DA reached a maximum at $\mathrm{pH} 7.0$ and then decreased with the change of $\mathrm{pH}$. Because $\mathrm{pH} 7.0$ was the physiological condition and the response current of DA was the highest at this $\mathrm{pH}$, it was chosen as the experiment $\mathrm{pH}$ value in the electrochemical detection of DA.

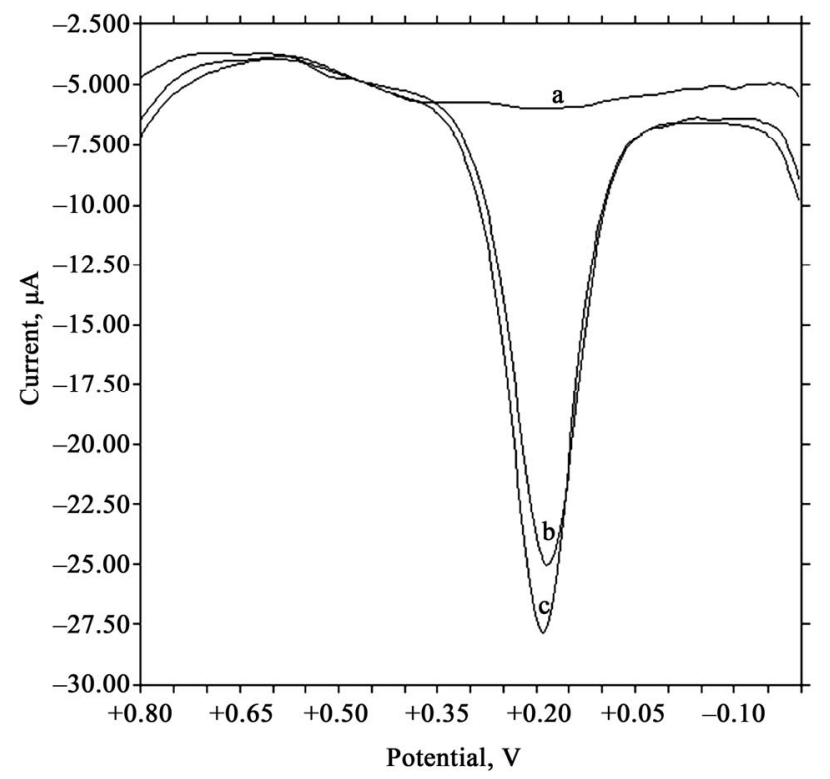

(a)

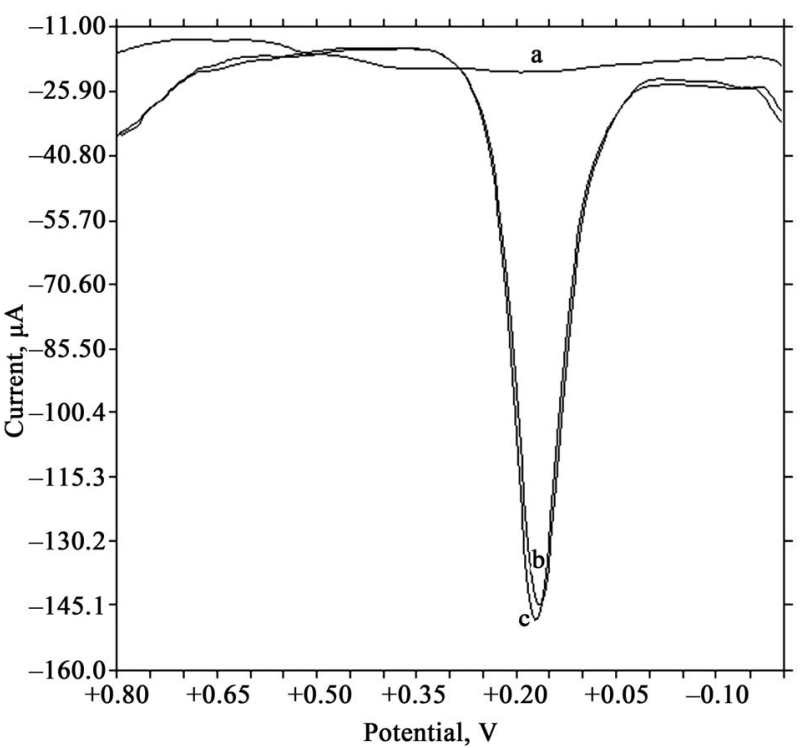

(b)

Figure 2. Differential pulse voltammograms of $D A$ and $A A$ at a bare GCE (a) and a poly(m-ABSA) film modified GCE (b) in $0.1 \mathrm{M}$ phosphate buffer solution (pH 7.0). (a) a: blank; b: 1 mM DA; c: 1 mM AA. (b) a: blank; b: 1 mM DA; c: 1 mM DA + 1 mM AA. 


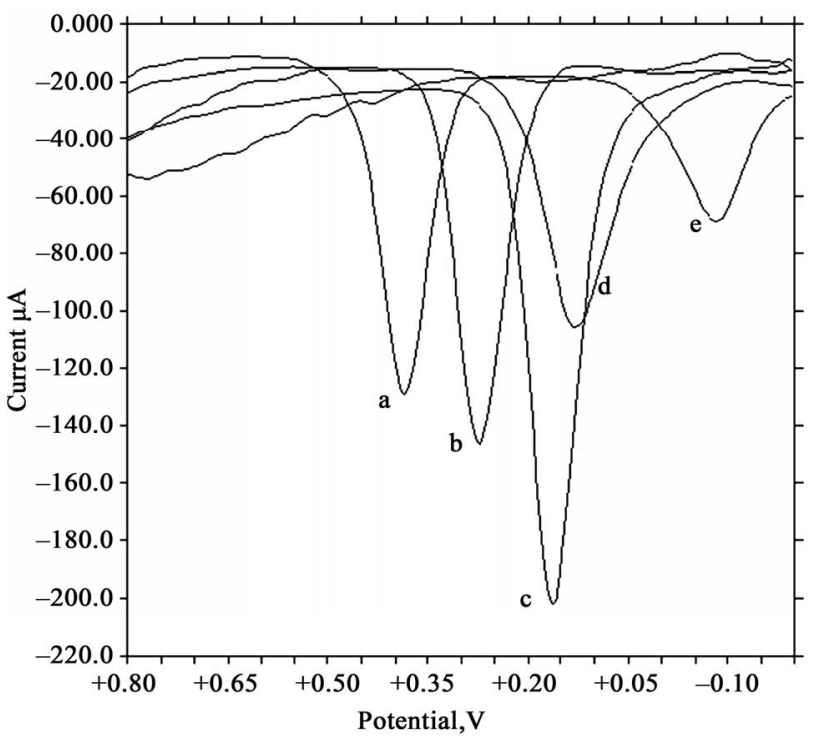

Figure 3. Differential pulse voltammograms of 1.0 mM DA at poly ( $m$-ABSA) modified electrode at different $\mathrm{pH}$ values (from a to e: 3.0, 5.0, 7.0, 9.0 and 11.0, respectively). The inset shows the dependence of the oxidized current versus pH of solution.

\subsubsection{Interference and Reproducibility Study}

In the extracellular fluid of the central nervous system, DA exists in only a nanomolar to micromolar range $(0.01$ - $1 \mu \mathrm{M})$ [32], whereas the concentration of AA is very high $(100-500 \mu \mathrm{M})$ [33]. As the main interference, AA hinders the accurate detection of DA because the oxidized DA product, dopamine- $O$-quinone, can be catalytically reduced to DA by AA that again becomes available for oxidation (as can be seen in Figure 2(b), the DA oxidized current increased when AA exists); however, when the concentration ratio of AA/DA is greater than 1 , this interference is constant [34]. We carefully examined the oxidation currents of DA at the poly $(m-\mathrm{ABSA})$ modified GCE in the presence of increasing concentrations of AA (Figure 4(a)). There is no obvious change in the oxidation currents of DA when the concentration of AA changed (when the concentration of DA was $50 \mu \mathrm{M}$, the concentration ratio of AA/DA was 10-20). Moreover, there was hardly any response for AA oxidation at the poly $(m$-ABSA) modified electrode. As can be seen in Figure 4(b), the oxidation currents of DA increased proportionally with DA's concentration while the peak current of AA remained constant, indicating that the poly ( $m$-ABSA) electrode was sensitive only to DA.

This means that in the real biological matrixes, where the AA level is usually more than three orders of magnitude larger than DA, the poly $(m$-ABSA) film modified electrode could be used for the determination of DA in the real sample. We also examined the influence of other substances on the signals of the DA and found that no interference occurred in the presence of the following substance: 1000 -fold $\mathrm{NaCl}, 1000$-fold $\mathrm{NaNO}_{3}, 1000$-fold $\mathrm{NaClO}_{4}, 1000$-fold $\mathrm{Na}_{2} \mathrm{SO}_{4}$ and 1000 -fold $\mathrm{KCl}$.

One of the problems of determination of DA by the bare electrode is the fouling of electrode surface, but in our experiment we did not notice the inhibition of the activity of the modifier toward DA detection; the peak current of DA remained constant after the scan cycles of

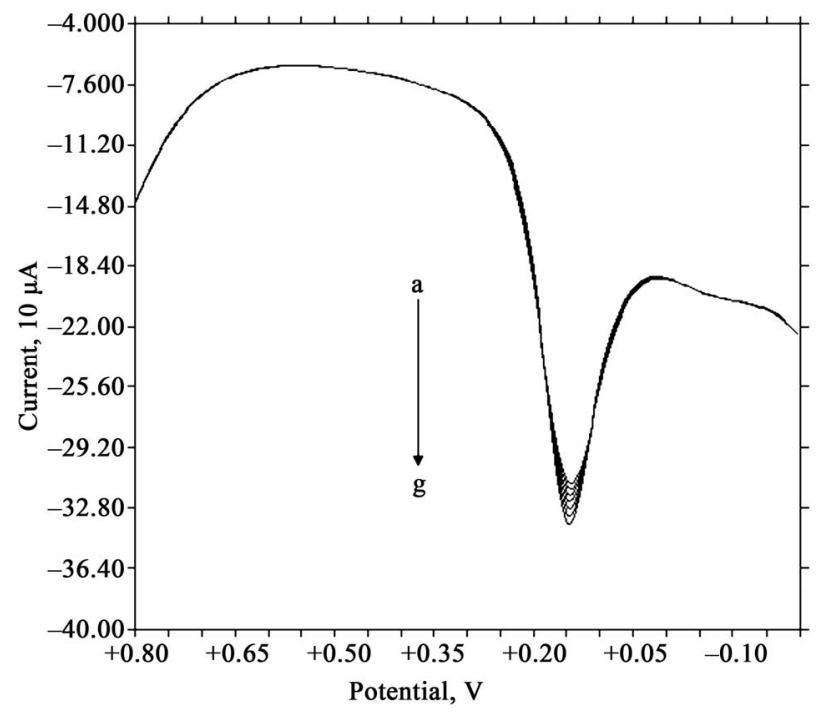

(a)

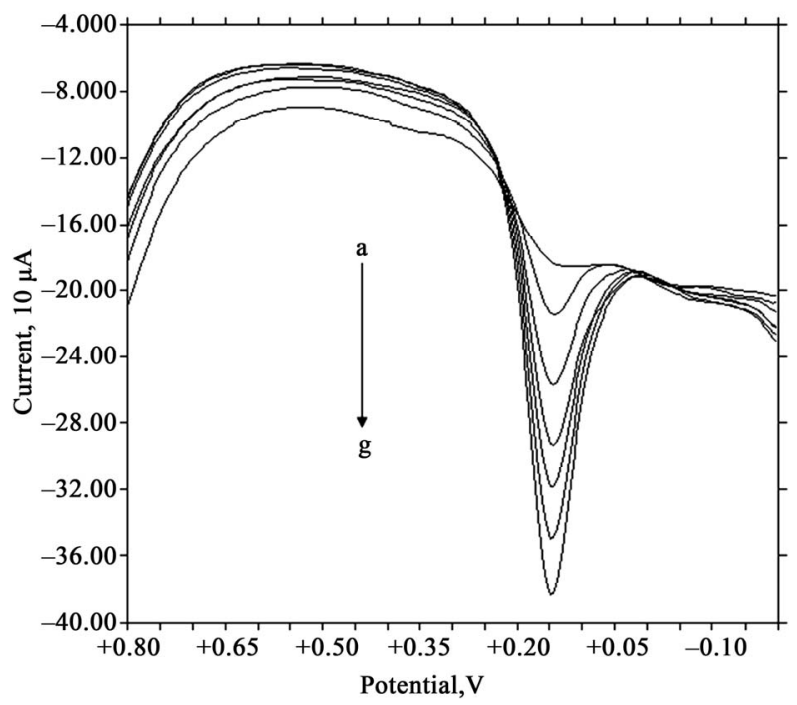

(b)

Figure 4. (a) Differential pulse voltammograms at poly ( $m$-ABSA) modified GCE in $\mathbf{p H}$ 7.0 phosphate buffer solution containing $50 \mu \mathrm{M}$ DA in the presence of different concentrations of AA: a. $0 \mu \mathrm{M}$ b. $500 \mu \mathrm{M}$ c. $600 \mu \mathrm{M}$ d. $700 \mu \mathrm{M}$ e. $800 \mu \mathrm{M}$ f) $900 \mu \mathrm{M}$ and g) $1000 \mu \mathrm{M}$. (b) Differential pulse voltammograms at poly ( $m$-ABSA) modified GCE in pH 7.0 phosphate buffer solution containing $1 \mathrm{mM} \mu \mathrm{MAA}$ in the presence of different concentrations of DA: a. $0 \mu \mathrm{M}$ b. $5 \mu \mathrm{M}$ c. $10 \mu M$ d. $15 \mu M$ e. $20 \mu M$ f. $25 \mu M$ and g. $30 \mu M$. 
cyclic voltammograms up to 7 times (see Figure 5). This can be explained as shown by the equations in Scheme 1 [13]. When the DA is oxidized (Equation (1)), its oxidation product, dopaminequinone, can undergo followup ring closure reaction (Eqaution (2)), leading to leucodopaminechrome [35], which in turn is oxidized to dopaminechrome (Equation (3)). It is required that the protonated side chain of dopaminequinone move toward the quinone ring. But at the poly $(m-\mathrm{ABSA})$ modified electrode, the high density of negatively charged groups in the film is likely to immobilize the chain or at least suppress its mobility and, thus, prevent the reaction given by Equation (2) and, consequently, all of the follow-up reactions.

\subsubsection{Determination of $D A$}

The determination of DA concentration at the poly ( $m$-ABSA) modified electrode was performed with differential pulse voltammetry. The anodic peak current was linear to DA concentration in the ranges of $1.0 \times 10^{-7}$ to $5.0 \times 10^{-5}$ $\mathrm{M}$ and $5.0 \times 10^{-5}$ to $1.0 \times 10^{-4} \mathrm{M}$. The linear regression
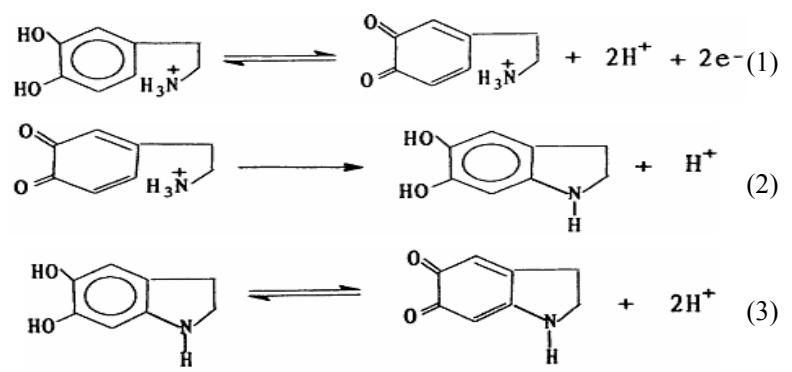

Scheme 1. Possible reaction procedure of DA on the electrode.

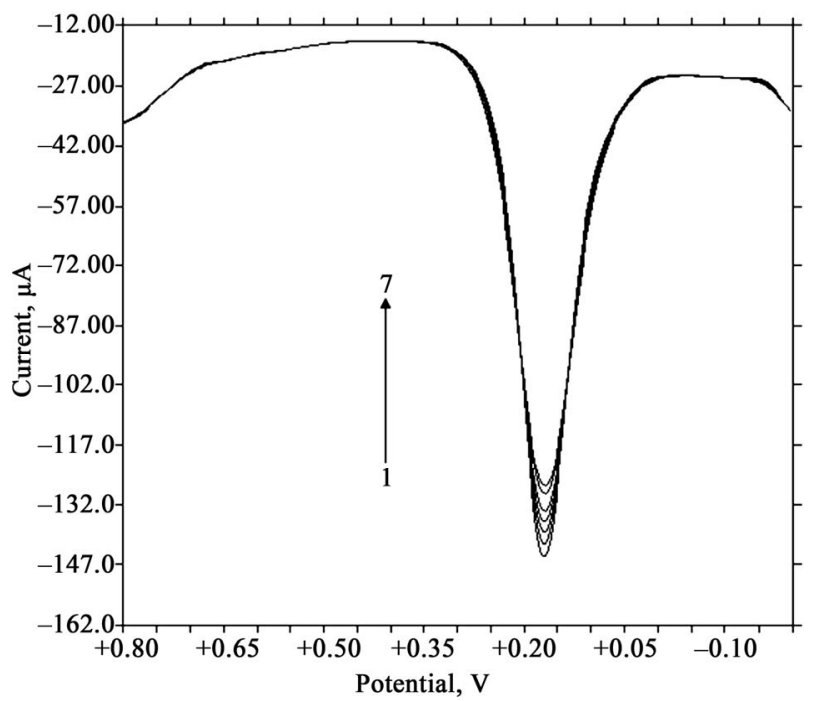

Figure 5. Repetitive differential pulse voltammograms of 1 mM DA at poly $(m-A B S A)$ modified electrode in $0.1 \mathrm{M}$ phosphate buffer solution $(\mathrm{pH}=\mathbf{7 . 0})$.
Table 1. Determination of DA in Injections.

\begin{tabular}{ccccc}
\hline $\begin{array}{c}\text { DA specified } \\
\left(\times 10^{-5} \mathrm{~mol} \mathrm{~L}^{-1}\right)\end{array}$ & Added & $\begin{array}{c}\text { Found } \\
\left(\times 10^{-5} \mathrm{~mol} \mathrm{~L}^{-1}\right)\end{array}$ & $\begin{array}{c}\text { R.S.D. } \\
\left(\times 10^{-5} \mathrm{~mol} \mathrm{~L}^{-1}, \mathrm{n}=5\right)\end{array}$ & $\begin{array}{c}\text { Recovery } \\
(\%)\end{array}$ \\
\hline 5.00 & 1.0 & 6.09 & 3.82 & 101.5 \\
5.00 & 2.0 & 6.98 & 3.45 & 99.71 \\
5.00 & 3.0 & 7.97 & 3.02 & 99.63 \\
\hline
\end{tabular}

equations were ip $(10 \mu \mathrm{A})=0.9879+0.4874 \mathrm{C}(10 \mu \mathrm{M})$ $\left(r^{2}=0.9937\right)$ and ip $(10 \mu \mathrm{A})=4.3189+0.3456 \mathrm{C}(10$ $\mu \mathrm{M})\left(r^{2}=0.9882\right)$, respectively. The detection limit was $5.0 \times 10^{-9} \mathrm{M}$.

The relative standard deviation of 7 successive scans was $3.5 \%$ for $1.0 \times 10^{-5} \mathrm{M} \mathrm{DA}$, indicating that the poly ( $m$-ABSA) modified electrode had excellent reproducibility. Furthermore, the stability of the modified electrode was investigated.

\subsubsection{Analytical Applications}

The injections of DA were analyzed by the standard addition method. The results are shown in Table 1. The recovery and relative standard deviation values were acceptable, showing that the proposed methods could be efficiently used for the determination of DA in injections.

\section{Conclusions}

This study has indicated that the poly $(m$-ABSA) film exhibits highly electrocatalytic activity to the oxidation of DA. The modified electrode provides greater sensitivity and selectivity in the determination of DA. The interference of AA could be eliminated due to the very favorable electrostatic interaction between the negatively charged poly ( $m$-ABSA) film and cationic species of DA or anionic species of AA in phosphate buffer solution at $\mathrm{pH}$ 7.0. Moreover, the modified electrode showed good reproducibility and stability. The proposed methods can be applied to the detection of DA in the presence of excess AA in real samples.

\section{Acknowledgements}

This study was financially supported by the Research Fund Unit of İnönü University (Grant no APYB: 2008/ 48).

\section{References}

[1] R. M. Wightman, L. J. May and A. C. Michael, "Detection of Dopamine Dynamics in the Brain," Analytical Chemistry, Vol. 60, No. 13, 1988, pp. 769-779. 
doi:org/10.1021/ac00164a001

[2] X. Cao, L. Luo, Y. Ding, X. Zou and R. Bian, "Electrochemical Methods for Simultaneous Determi- nation of Dopamine and Ascorbic Acid using Cetylpy-Ridine Bromide/chitosan Composite Film-Modified Glassy Carbon Electrode," Sensors and Actuators B, Vol. 129, No. 2, 2008, pp. 941-946. doi:org/10.1016/j.snb.2007.10.008

[3] T. Zetterstrom, T.Sharp, C. A. Marsden and U. Ungerstedt, "In vivo Measurement of Dopamine and Its Metabolites by Intracerebral Dialysis-Changes after D-Ampheta-Mine," Journal of Neurochemistry, Vol. 41, No. 6, 1983, pp. 1769-1773.

doi:org/10.1111/j.1471-4159.1983.tb00893.x

[4] F. Malem and D. Mandler, "Self-Assembled Monolayers in Electroanalytical Chemistry-Application of OmegaMercapto Carboxylic-Acid Monolayers for the Electrochemical Detection of Dopamine in the Presence of A High-Concentration of Ascorbic-Acid," Analytical Chemistry, Vol. 65, No. 1, 1993, pp. 37-41.

[5] F. Gonon, M. Buda, R. Cespuglio, J. Jouvet and J. F. Pujol, "Differential Pulse Voltammetry in Brain-Tissue 1. Detection of 5-Hydroxyindoles in the Rat Striatum," Brain Research, Vol. 223, No. 2, 1981, pp. 69-80. doi:org/10.1016/0006-8993(81)90807-6

[6] R. A. Saraceno, J. G. Pack and A. G. Ewing, "Catalysis of Slow Charge-Transfer Reactions at Polypyrrole-Coated Glassy-Carbon Electrodes," Journal of Electroanalytical Chemistry, Vol. 97, No. 1-2, 1986, pp. 265-278. doi:org/10.1016/0022-0728(86)80154-1

[7] G. Erdogdu, H. B. Mark and A. E. Karagozler, "Resolution of Ascorbic Acid and Dopamine at Conducting Polymer Electrodes," Analytical Letters, Vol. 29, No. 2, 1996, pp. 221-231.

[8] G. Erdogdu and A. E. Karagozler, "Investigation and Comparison of the Electrochemical Behavior of Some Organic and Biological Molecules at Various Conducting Polymer Electrodes," Talanta, Vol. 44, No. 11, 1997, pp. 2011-2018.

[9] G. Erdogdu, E. Ekinci and A. E. Karagozler, "Preparation and Electrochemical Behavior of Dopamine-Selective Polymeric Membrane," Polymer Bulletin, Vol. 44, No. 2, pp. 195-201.

[10] E. Ekinci, G. Erdogdu and A. E. Karagözler, "Preparation, Optimization, and Voltammetric Characteristics of Poly (o-phenylenediamine) Film as a Dopamine-Selective Polymeric Membrane," Journal of Applied Polymer Science, Vol. 79, No. 2, 2001, pp.327-332. doi:org/10.1002/1097-4628(20010110)79:2<327::AID-A PP150>3.0.CO;2-Z

[11] E. Ekinci, G. Erdogdu and A. E. Karagozler, "Investigation of Polymerization Parameters Affecting Dopamine Selectivity of a Polymeric Membrane," Polymer Bulletin, Vol. 44, No. 5-6, 2000, pp. 547-553. doi:org/10.1007/s002890070077

[12] G. Erdogdu and A. E. Karagozler, "Investigation of the Voltammetric Characteristics of Poly (1,4-Diaminobenzene) Film as a Dopamine-Selective Polymer Electrode,"
Turkish Journal of Chemistry, Vol. 31, No. 2, 2007, pp. 171-178. doi:org/10.1021/ac9808223

[13] A. Ciszewski and G. Milczarek, "Polyeugenol-Modified Platinum Electrode for Selective Detection of Dopamine in the Presence of Ascorbic Acid," Analytical Chemistry, Vol. 71, No. 5, 1999, pp. 1055-1061.

[14] H. Zhao, Y. Z. Zhang and Z. B. Yuan, "Determination of Dopamine in the Presence of Ascorbic Acid using Poly(Hippuric Acid) Modified Glassy Carbon Electrode," Electroanalysis, Vol. 14, No. 14, 2002, pp.1031-1034.

[15] H. Zhao, Y. Z. Zhang and Z. B. Yuan, "Electrochemical Determination of Dopamine Using a Poly (2-picolinic acid) Modified Glassy Carbon Electrode," Analyst, Vol. 126, No. 3, 2001, pp. 358-360.

[16] H. Zhao, Y. Z. Zhang and Z. B. Yuan, "Study on the Electrochemical Behavior of Dopamine with Poly(Sulfosali-Cylic Acid) Modified Glassy Carbon Electrode," Analytica Chimica Acta, Vol. 441, No. 1, 2001, pp. 117-122. doi:org/10.1016/S0003-2670(01)01086-8

[17] U. Chandra, B. E. K. Swamy, O. Gilbert and B. S. Sherigara, "Voltammetric Resolution of Dopamine in the Presence of Ascorbic Acid and Uric Acid at Poly (Calmagite) Film Coated Carbon Paste Electrode," Electrochimica Acta, Vol. 55, No. 24, 2010, pp. 7166-7174. doi:org/10.1016/j.electacta.2010.06.091

[18] A. J. Downard, A. D. Roddick and A. M. Bond, "Covalent Modification of Carbon Electrodes for Voltammetric Differentiation of Dopamine and Ascorbic Acid," Analytica Chimica Acta, Vol. 317, No. 1-3, 1995, pp. 303-310.

[19] M. J. Giz, B. Duong and N. J. Tao, "In Situ STM Study of Self-Assembled Mercaptopropionic Acid Monolayers for Electrochemical Detection of Dopamine," Journal of Electroanalytical Chemistry, Vol. 465, No. 1, 1999, pp. 72-79. doi:org/10.1016/S0022-0728(99)00056-X

[20] K. T. Kawagoe and R. M. Wightman, "Characterization of Amperometry for in-vivo Measurement of Dopamine Dynamics in the Rat-Brain," Talanta, Vol. 41, No. 2, 1994, pp. 865-874.

[21] G. A. Gerhardt, A. F. Oke, G. Nagy, B. Moghaddam and R. N. Adams, "Nafion-Coated Electrodes with High Selectivity for CNS Electrochemistry," Brain Research, Vol. 290, No. 2, 1984, pp. 390-395. doi:org/10.1016/0006-8993(84)90963-6

[22] J. A. Ni, H. X. Ju, H. Y. Chen and D. Leech, "Electrocatalytic Oxidation and Trace Determination of Catecholamine Neurotransmitters at Osmium Complex Polymer and Nafion Dual-layer Membrane Carbon-Base electrode," Chemical Journal of Chinese Universities-Chinese, Vol. 20, No. 2, 1999, pp. 224-226.

[23] J. Wang and T. Z. Peng, "Selectivity and Sensitivity Improvements at Perfluorinated Ionomer Cellulose-Acetate Bilayer Electrodes," Analytical Chemistry, Vol. 58, No. 14, 1986, pp. 3257-3261. doi:org/10.1021/ac00127a076

[24] A. R. Guadalupe and H. D. Abruna, "Electroanalysis with Chemically Modified Electrodes," Analytical Chemistry, Vol. 57, No. 1, 1985, pp. 142-149.

[25] Z. Salamon and G. Tollin, "Reduction of Cytochrome-C 
at a Lipid Bilayer Modified Electrode," Bioelectrochemistry and Bioenergetics, Vol. 25, No. 3, 1991, pp. 447454. doi:org/10.1016/0302-4598(91)80009-R

[26] J. A. Ni, H. X. Ju, H. Y. Chen and D. Leech, "Amperometric Determination of Epinephrine with an Osmium Complex and Nafion Double-Layer Membrane Modified Electrode," Analytica Chimica Acta, Vol. 378, No. 1-3, 1999, pp. 151-157. doi:org/10.1016/S0003-2670(98)00569-8

[27] Q. D. Huang, Z. Q. Lu and J. F. Rusling, "Composite Films of Surfactants, Nafion, and Proteins with Electrochemical and Enzyme Activity," Langmuir, Vol. 12, No. 22, 1996, pp. 5472-5480.

[28] Y. Z. Zhang, G. Y. Jin, Y. L. Wang and Z. S. Yang, "Determination of Dopamine in the Presence of Ascorbic Acid using Poly (Acridine Red) Modified Glassy Carbon Electrode," Sensor, Vol. 3, 10, 2003, pp. 443-450.

[29] P. R. Roy, T. Okajima and T. Ohsaka, "Simultaneous Electroanalysis of Dopamine and Ascorbic Acid using Poly (N,N-Dimethylaniline)-Modified Electrodes," Bioelectrochemistry, Vol. 59, No. 1-2, 2003, pp. 11-19.

[30] H. Zhao, Y. Z. Zhang and Z. B. Yuan, "Study on the Electrochemical Behavior of Dopamine with Poly(Sulfosali-Cylic Acid) Modified Glassy Carbon Electrode, Analytica Chimica Acta, Vol. 441, No. 1, 2001, pp.

\section{7-122. doi:org/10.1016/S0003-2670(01)01086-8}

[31] H. Zhao, Y. Z. Zhang and Z. B. Yuan, "Electrochemical Determination of Dopamine using a Poly(2-picolinic acid) Modified Glassy Carbon Electrode," Analyst, Vol. 126, No. 3, 2001, pp. 358-360.

[32] P. Capella, B. Ghasemzadeh, K. Mitchell and R. N. Adams, "Nafion-Coated Carbon-Fiber Electrodes for Neurochemical Studies in Brain-Tissue," Electroanalysis, Vol. 2, No. 3, 1990, pp. 175-182.

[33] R. D. O'Neill, "Microvoltammetric Techniques and Sensors for Monitoring Neurochemical Dynamics in vivo —a Review," Analyst, Vol. 119, No. 1, 1994, pp. 767-779.

[34] Y. H. Xiao, C. X. Guo, C. M. Li, Y. B. Li, J. Zhang, R. H. Xue and S. Zhang, "Highly Sensitive and Selective Method to Detect Dopamine in the Presence of Ascorbic Acid by a New Polymeric Composite Film," Analytical Biochemistry, Vol. 371, No. 2, 2007, pp. 229-237. doi:org/10.1016/j.ab.2007.07.025

[35] E. S. Forzani, G. A. Rivas G. A and V. M. Solis, "Amperometric Determination of Dopamine on Vegetal-Tissue Enzymatic Electrodes. Analysis of Interferents and Enzymatic Selectivity," Journal of Electroanalytical Chemistry, Vol. 435, No. 1-2, 1997, pp. 77-84. doi:10.1016/S0022-0728(97)00049-1 